\title{
Structural, compositional and electrochemical properties of Aluminium-Silicon-Chromium alloy thin film as anode for Lithium thin film battery
}

\author{
Atul Killedar ${ }^{1}$ Arun Patil ${ }^{2}$, Vaishali Patil ${ }^{3}$, Ji-Won Choi ${ }^{4}$, and ${ }^{4}$ Seok-JinYoon ${ }^{4}$ \\ ${ }^{1,2}$ Vishwakarma College of Arts Commerce and Science, Kondhwa Bk. Pune, India \\ ${ }^{3}$ Vishwakarma Institute of Information Technology, Kondhwa Bk. Pune, India \\ ${ }^{4}$ Thin Film Materials Research Center, Korea Institute of Science and Technology, Seoul South Korea, 136- 791
}

\begin{abstract}
In recent years, many new materials have been investigated in order to meet the need of high energy density for thin film batteries. Silicon based anode materials are attracting wide attention because of the highest theoretical capacity. By using DC magnetron sputtering method Aluminium film was deposited on ceramic substrate which acts as a current collector. Nanocrystalline film of Aluminium-Silicon-Chromium(Al-Si-Cr) alloy was deposited on aluminum film by using same sputtering method. High purity Aluminium-SiliconChromium metal alloy sputtering target was used for the film deposition. For comparison of anode cycling performance, pure Silicon thin films were also prepared by using same sputtering method. Al-Si-Cr films were analysed by XRD, EDAX, AFM and SEM . The crystallite size was determined by FWHM of XRD peaks. Particle size and microstructure of the film have been studied by SEM and AFM. The Al-Si-Cr thin film composition was analysed by EDAX. Composition ratio between Aluminium Silicon and Chromium obtained by EDAX is 2:3:5. Electrochemical properties of the films were analyzed by preparing lithium battery cell. Lithium insertion and excretion was performed by Cyclic Voltametry.
\end{abstract}

Effect of cycling on structure stability of Al-Si-Cr anode film was studied by SEM analysis.

Keywords: anode , Al-Si-Cr alloy,thinfilm, battery, lithium , magnetron sputtering ,

\section{Introduction}

In last decade, focused research has been conducted on thin-film micro batteries as a power source for Microsystems [1-3]. Subsequently, there have been considerable efforts in finding new materials to replace the existing lithium battery anode [4-10].

It is already known that as a naturally abundant element, $\mathrm{Si}$ has the highest theoretical specific capacity among all exiting anodes, which can reach $4200 \mathrm{mAh} / \mathrm{g}$ in the form of $\mathrm{Li}_{4.4} \mathrm{Si}$ [11-16]. Unfortunately, its potential in broad commercial applications has been hindered by severe capacity fading and loss of electrical contact caused by huge volume change, structural crumbling and cracking during repeated charging/discharging, especially at high currents .It could be overcome by using a multiple-layer thin comprising a silicon ( $\mathrm{Si}$ ) layer and a transition metal (M) layer[17-18]. Where metal (M) is incompatible with Lithium. This leads to the question whether the metal (M) layer can act as a diffusion barrier against $\mathrm{Li}$ penetration during $\mathrm{Li}$ insertion/extraction reactions of the multilayer film electrode. Another approach for solving the problem of silicon capacity fading is using ternary alloy materials as anodes. Some researchers have reported their work of ternary system with Al-Si-Mn [19-20]. Consequently, these anodes presented poor cycle performances. For example, the first discharge specific capacity of the $\mathrm{Al}_{59} \mathrm{Si}_{40} \mathrm{Mn}_{1}$ anodes could achieve $1803 \mathrm{~mA} \cdot \mathrm{h} / \mathrm{g}$, but declined to $636 \mathrm{mAh} / \mathrm{g}$ in the next cycle. As a result, a low specific capacity of $125 \mathrm{mAh} / \mathrm{g}$ was shown after 10 cycles. Hence a substitution for the third inert component in place of Mn might be an effective method to obtain better cycle performances.According to the binary alloy phase diagrams [21], the solubility of $\mathrm{Li}$ in $\mathrm{Cr}$ is less than that in $\mathrm{Mn}$. In this paper the DC magnetron sputtered film of $\mathrm{Al}-\mathrm{Si}-\mathrm{Cr}$ alloy is investigated as anode material for lithium-ion battery.

\section{Experimental details}

All the films were deposited using DC magnetron sputtering technique. The target used (metal alloy to be deposited) was with $20 \mathrm{Wt} \%$ Aluminium, $30 \mathrm{Wt} \%$ Silicon and $50 \mathrm{Wt} \%$ Chromium make M/s Heraus Germany. \{Purity of each individual metal was $99.99 \%$ \}. The pure Aluminum target \{purity $99.99 \%$ \} was from M/s Kistar,Korea.The substrate used was alumina containing ceramic plate supplied by M/s Murata,Japan.The surface roughness of ceramic plate was $0.180 \mu \mathrm{m}$. The sputtering equipment used was of Balzer make. This sputtering technique uses an inert gas which is ionised under application of high voltage under vacuum. Argon gas is selected, as argon ions are heavy enough to knock metal atoms out of target.Ions are attracted by target which has negative voltage and are accelerated under influence of magnet fitted above target. For Al-Si-Cr thin 
film deposition extensive trials were conducted with varying sputtering parameters .Optimum parameters were derived to get best possible and stable film morphology. Following optimized parameters were employed for deposition of $\mathrm{Al}-\mathrm{Si}-\mathrm{Cr}$ films.

Argon Gas Purity- $99.99 \%$,Argon Gas pressure - 5mTorr ,Sputtering Power- 150 watt, Sputter deposition time -60 min , Extent of Vacuum in sputtering chamber- $3 \times 10^{-6}$ bar.No post heat treatment was given to films.

For comparison of anode cycling performance pure Silicon thin films were also prepared by using same sputtering method.Pure Silicon sputtering target \{purity $99.99 \%$ \} was also supplied by M/s Heraus, Germany

The composition of deposited $\mathrm{Al}-\mathrm{Si}-\mathrm{Cr}$ and aluminum films was characterized by energy dispersive $\mathrm{X}$ ray analysis (EDAX) to ensure identical composition of the starting target and the deposited films. The surface microstructure was determined by SEM and AFM. The XRD experiments were carried out with CuKa radiation. Cyclicvoltammetry (CV) properties were measured with the cell which was composed of a metal Lithium foil as a counter electrode. $1 \mathrm{MLiPF}_{6}$ in 1:1 (v/v) mixture of ethylene carbonate (EC) and diethyl carbonate (DEC) was used as Electrolyte. Cells were fabricated to test the electrochemical properties of thin-film electrodes. The cells were assembled in an argon filled glove-box. AFM and SEM images of Al-Si-Cr and Aluminum films were taken before and after cycling.

\section{Results and discussion}

An X-ray diffraction pattern of Al-Si-Cr thin film is shown in Figure 1.It demonstrates thin films with crystalline aluminum peaks according to JCPDS 04-0787[22]. Peaks for the (111), (200), and (220) are clearly observed in the XRD plots below. Note that a broad peak accompanied by stronger, sharper peaks around 65 degrees is generated due to the silicon. Thin films deposited on ceramic and aluminum nitride substrate had a dominant (111) orientation,. It was expected for sputtered aluminum-silicon-chromium films to be highly crystalline in this respect. From the width of the diffraction peaks, the average grain size was calculated according to the Scherrer equation (crystallite size $\mathrm{D}=0.9 \lambda=\mathrm{B} \operatorname{Cos} \theta$ ). The estimated average crystallite size for the Al-Si-Cr alloy deposited thin film is about $45 \mathrm{~nm}$. Composition ratio between Aluminium ,Silicon and Chromium was obtained by EDAX as shown in Figure 2. The EDAX spectrum shows that elemental composition of deposited $\mathrm{Al}-\mathrm{Si}-\mathrm{Cr}$ film is in good agreement with composition of starting $\mathrm{Al}-\mathrm{Si}-\mathrm{Cr}$ metal alloy target composition. The AFM image of the Al-Si-Cr thin film is shown in Figure 3.It shows that root mean square roughness $\mathrm{Rq}$ is $23.2 \mathrm{~nm}$ and indicates that the deposited film is very smooth and uniform. SEM image in Figure 4 also confirms that $\mathrm{Al}-\mathrm{Si}-\mathrm{Cr}$ is deposited as a uniform matrix.

The $\mathrm{Li}$ insertion/removal into the film was done by CyclicVoltametry. Figure 5 shows CV voltamogram .From the $\mathrm{CV}$ results, it can be seen that $\mathrm{Li}$ insertion reaction occurred mostly at low potential below $0.2 \mathrm{~V}$. The peaks obtained are attributed to the potential dependent formation and disappearance of $\mathrm{Li}-\mathrm{Si}$ alloys of different compositions given by Wen and Huggins [23]. The difference in the potential for each peak can be ascribed to the kinetic effect involved in the CV measurement [24]. The peaks observed on the second cycle were compared with the first cycle in that two cathodic/anodic peaks decrease significantly at $0.2 / 0.3 \mathrm{~V}$ and an anodic peak at $0.5 \mathrm{~V}$ shifts toward a higher potential.The irreversible reaction of the first cycle seems to be associated with the formation of a solid electrolyte interface (SEI)layer or dangling bond which is related to phase transformation [25]. Therefore, the significant reduction of peak at $0.2 \mathrm{~V}$ indicated that the irreversible reaction was suppressed by maintaining the equilibrium state in the second cycle. The potential shift of about $0.1 \mathrm{~V}$ from 0.5 to $0.6 \mathrm{~V}$ also indicates increased kinetic polarization and internal resistance.

The discharge capacity of Al-Si-Cr anode as a function of the number of cycles is shown in Figure 6. It is observed that $\mathrm{Al}-\mathrm{Si}-\mathrm{Cr}$ films gradually degraded with cycling. However, $\mathrm{Al}-\mathrm{Si}-\mathrm{Cr}$ thin film anode showed higher discharge capacity and capacity retention as compared to the pure silicon thin film anode. Pure Silicon thin film anode cycling data was comparable with data reported in other literature [26-28].Capacity retention after 50 number of cycles for $\mathrm{Al}-\mathrm{Si}-\mathrm{Cr}$ anode was $77 \%$ and that for pure Silicon anode was $52 \%$. SEM analysis was performed on $\mathrm{Al}-\mathrm{Si}-\mathrm{Cr}$ anode film after cycling. Figure 7 shows the SEM micrographs of $\mathrm{Al}-\mathrm{Si}-\mathrm{Cr}$ anode film before and after cycling. It clearly shows that due to cycling stress film structure is changed.The sharp grain boundaries collapsed and got merged in each other suggesting starting of loss adhesion between substrate and anode film[29]. 


\section{Figures and Table}

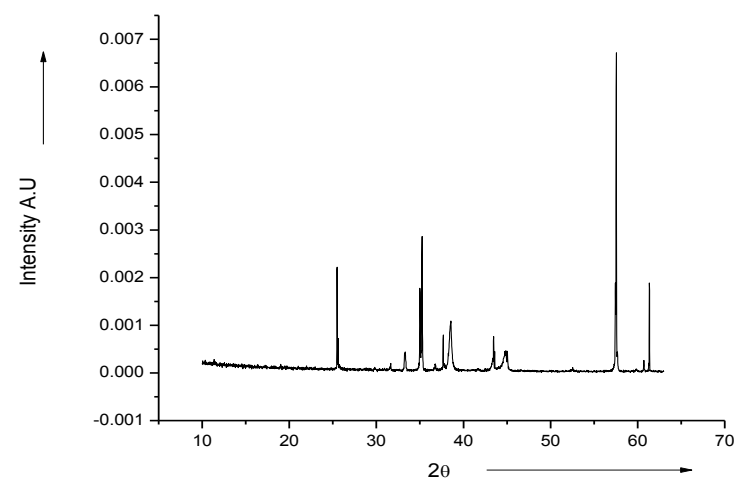

Fig1:XRD plot of Al-Si-Cr thin film

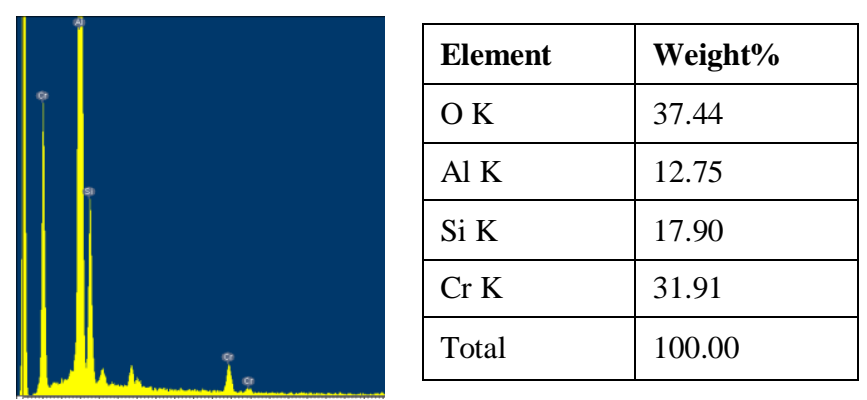

Fig2:EDAX spectrum of Al-Si-Cr thin film on ceramic substrate

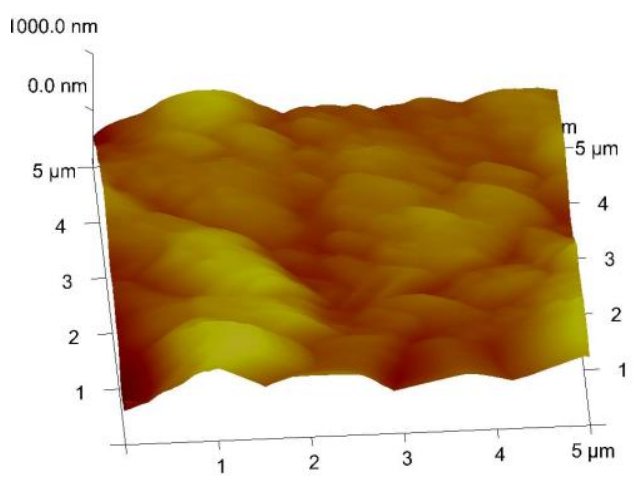

Fig3:AFM image of Al-Si-Cr thin film

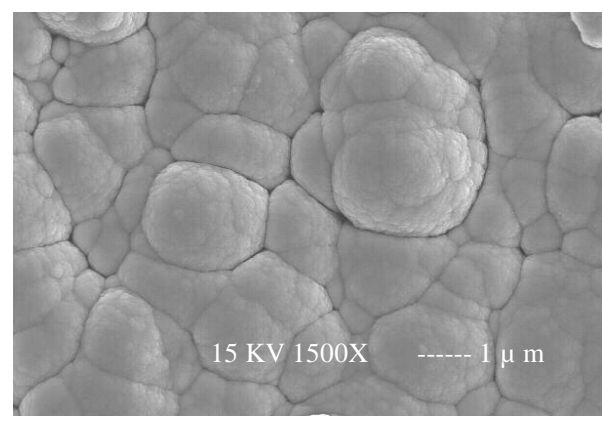

Fig 4: SEM micrograph of Al-Si-Cr thin film 


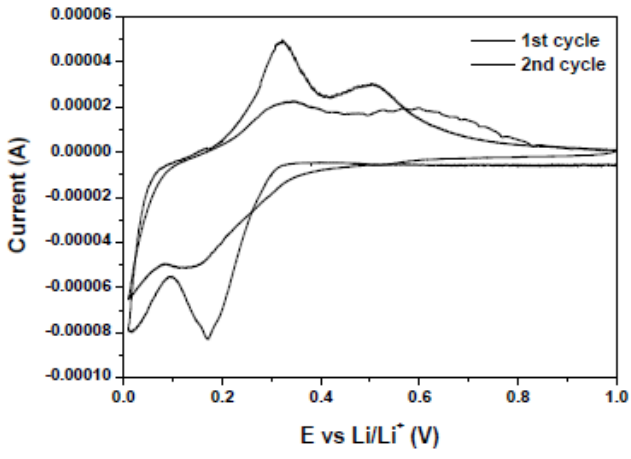

Fig. 5: The cyclic voltamogram of Al-Si-Cr thin film

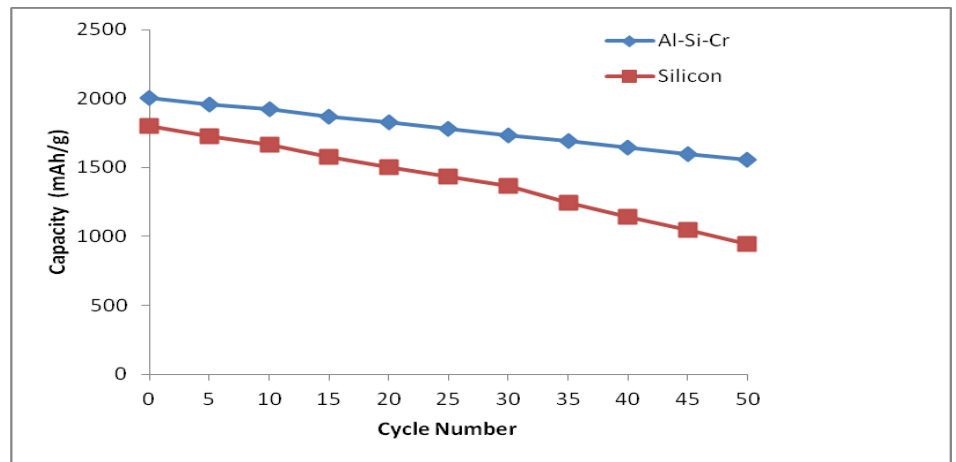

Fig 6: Cycling performance of $\mathrm{Al}-\mathrm{Si}-\mathrm{Cr}$ and pure Silicon anodes
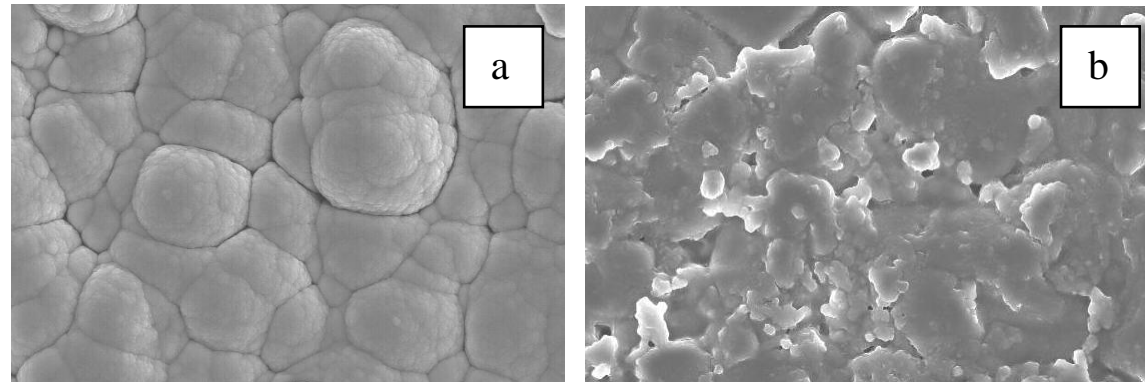

Fig 7: SEM micrographs of before and after cycling of Al-Si-Cr anode a. Before cycling

b. After cycling

\section{Conclusions}

Stable thin films of pure Aluminum and Al-Si-Cr metal alloy were successfully prepared using DC magnetron sputtering.XRD studies confirmed that the grain size of $\mathrm{Al}-\mathrm{Si}-\mathrm{Cr}$ film is in the nanometer range. The electrochemical properties and micro structural stability of a $\mathrm{Al}-\mathrm{Si}-\mathrm{Cr}$ film have been investigated. Cyclic voltammetry studies have confirmed that $\mathrm{Al}-\mathrm{Si}-\mathrm{Cr}$ thin films are active towards Lithium. Capacity vs.cycle study suggests that Al-Si-Cr has significant higher performance in terms of initial discharge capacity and capacity retention. We believe that further optimization of substrate surface morphology will lead to better adhesion of anode leading to improvements in cycling performance.

\section{REFERENCES}

[1] S.D. Jones and J.R. Akridge, Solid State Ionics, 53, 1992,628

[2] J.B. Bates, N.J. Dudney, G.R. Gruzalski, R.A. Zuhr, A.Choudunry, C.F. Luck and J.D. Robertson, J. Power Sources, 43, 1999,103,

[3] J.B. Bates, N.J. Dudney, B.J. Neudecker, F.X. hart, H.P.Jun and S.A. Hackney, J. Electrochem. Soc., 147, 2000 ,59 .

[4] B.J. Neudecker, R.A. Zuhr and J.B. Bates, J. PowerSources, 81, 1999,27

[5] J.B. Bates, N.J. Dudney, B. Neudecker, A. Ueda and C.D. Evans, Solid State Ionics, 135, 2000,33

[6] J. Lee, H.Y. Lee, S.H. Jeong, H.K. Baik and S.M. Lee, J.Power Sources, 11, 2002,345.

[7] Y.L. Kim, S.J. Lee, H.K. Baik and S.M. Lee, J. PowerSources, 119, 2003,106

[8] S.J. Lee, H.Y. Lee, H.K. Baik and S.M. Lee, J. PowerSources, 119, 2003,113).

[9] S. Ohara, J. Suzuki, K. Sekine and T. Takamura, J. PowerSources, 119, 2003,591

[10] J.P. Maranchi, A.F. Hepp and P.N. Kumta, Electrochem.Solid-State Lett., 6, 2003, A198. 
[11] C.K. Chan, H. Peng, G. Liu, K.McIlwrath, X.F. Zhang, R.A. Huggins, Y. Cui, Nature Nanotechnology 3,2008,31-35.

[12] L. Ji, X. Zhang, Energy \& Environmental Science 3, 2010,124-129.

[13] U. Kasavajjula, C. Wang, A.J. Appleby, Journal of Power Sources 163 ,2007,1003-1039.

[14] R. Teki, M.K. Datta, R. Krishnan, T.C. Parker, T.M. Lu, P.N. Kumta, N. Koratkar, Small 5,2009,2236-2242.

[15] L. Hu, H. Wu, Y. Gao, A. Cao, H. Li, J. McDough, X. Xie, M. Zhou, Y. Cui, Advanced Energy Materials 1,2011,523-527.

[16] L. Ji, Z. Lin, M. Alcoutlabi, X. Zhang, Energy \& Environmental Science 4, 2011,2682-2699.

[17] J.B. Kim, H.Y. Lee, K.S. Lee, S.H. Lim and S.M. Lee,Electrochem. Commun.,5,2003, 544

[18] J.B. Kim, B.S. Jun and S.M. Lee, Electrochim. Acta, 50,2005,3390.

[19] SUN Zhan-bo, WANG Xiao-dong, LI Xue-peng, ZHAO Ming-shu,LI Yan, ZHU Yao-min, SONG Xiao-ping. [J].Journal of Power Sources, 182,2008, 353-358.

[20] SUN Zhan-bo, LI Xue-peng, WANG Xiao-dong, HU Qing, ZHAO Ming-shu, ZHU Yao-min, LI Yan, SONG Xiao-ping. [J].Science in China Series E, 52(8),2009, 2288-2294.

[21] OKAMOTO H. Phase diagrams for binary alloys [M]. ASM International, 2000

[22] WANG Cheng-Long etal CHIN. PHYS. LETT. Vol. 26, No. 1,2009, 018102

[23] C.J. Wen, R.A. Huggins, J. Solid State Chem. 37, 1976,271.

[24] S. Ohara, J. Suzuki, K. Sekine, T. Takamura, J. Power Sources 591,2003,119-121

[25] H. Li, X. Huang, L. Chen, Z. Wu, Y. Liang, Electrochem. Solid-State Lett. 2, 1999,547.

[26] Xilin Chen etal ACS Nano . 4(9),2010, 5366-5372

[27] Po-Chiang Chen Nano Res. 4(3) 2011, 290-296.

[28] Sibani Lisa Biswal Chem. Mater. 24 ,2012, 2998-3003

[29] Victor Agubra and Jeffrey Fergus, Materials,6, 2013,1310-1325 